\title{
The effect of global warming and ocean acidification on nitrogen uptake and assimilation in coralline algae
}

\author{
S.M.HANSON ${ }^{1 *}$, C. SLAYMARK ${ }^{2}$, N.A. KAMENOS ${ }^{2}$ AND \\ B. THIBODEAU ${ }^{1}$ \\ ${ }^{1}$ Department of Earth Sciences, The University of Hong \\ Kong, Pok Fu Lam, Hong Kong \\ (*correspondance: shanson92@hku.hk) \\ ${ }^{2}$ School of Geographical and Earth Sciences, University of \\ Glasgow, Glasgow G12 8QQ, UK
}

Coralline algae are found globally from the poles to the tropics where they play important roles in biogeochemical cycling, habitat formation and ecosystem biodiversity. However, Like many organisms they are now under threat from global warming and ocean acidification. Numerous studies have investigated the effects of elevated temperatures and $p \mathrm{CO}_{2}$ on coralline algal calcification, however, the effect of these stressors on the nitrogen cycle in coralline algae is currently unknown.

To investigate, coralline algae were exposed to four different treatments representing combinations of current temperature and $p \mathrm{CO}_{2}$ (control) to those expected by 2100 for 6 weeks. They were incubated with $\mathrm{K}^{15} \mathrm{NO}_{3}$ and ${ }^{15} \mathrm{NH}_{4} \mathrm{Cl}$ to identify assimilation of nitrogen into their soft tissue. Additionally, uptake rates of nitrate and ammonium were measured over three hours for each treatment.

Our results indicate assimilation of labelled nitrogen during the incubation period; to the best of our knowledge, this is the first time coralline algae have been shown to assimilate nitrogen duing photosynthesis. Below, a clear difference in $\delta^{15} \mathrm{~N}(\%)$ in coralline algae soft tissue between enriched and non-enriched samples can be observed. Although $\delta^{15} \mathrm{~N}(\% \circ)$ differs between treatment this difference was not significant suggesting warming and acidification have a limited effect on nitrogen assimilation. However, once we assess uptake rates of nitrogen we will have a better understanding of how each treatment affects nitrogen cycling in coralline algae.

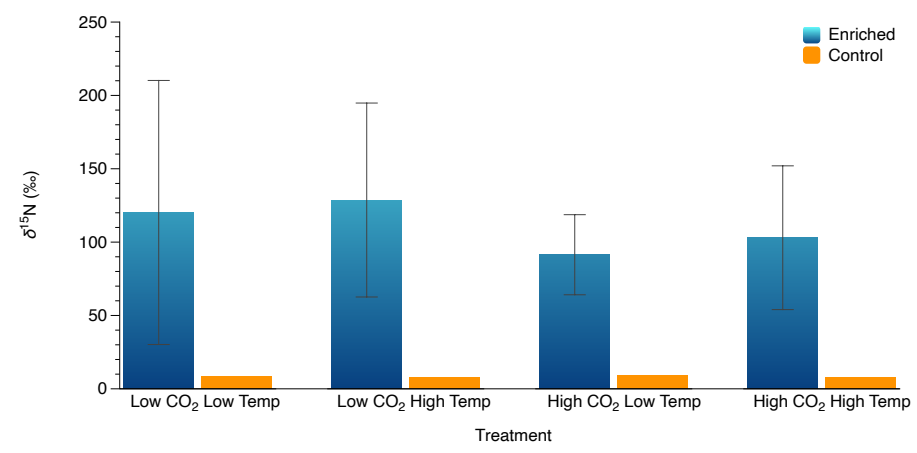

